\title{
Observation of the Near-Earth Plasmas by Telescope of Extreme Ultraviolet (TEX) Onboard SELENE: Science from the Moon
}

\author{
By Ichiro YoshiKawa ${ }^{1}$, Atsushi YamazaKI ${ }^{2)}$, Go MuraKami ${ }^{1)}$, Fukuhiro EzawA ${ }^{1)}$, Kazuo Yoshioka ${ }^{1)}$, \\ Shingo KAMEDA ${ }^{2)}$, Wataru MIYAKE ${ }^{3)}$, Makoto TAGUCHI ${ }^{4)}$, Masayuki $\mathrm{KIKUCHI}^{5)}$, \\ Masato NAKAMURA $^{2)}$, Takeshi SAKANOI ${ }^{6)}$ and Shoichi OKANO ${ }^{6}$ \\ ${ }^{1)}$ Department of Earth and Planetary Science, The University of Tokyo, Tokyo, Japan \\ ${ }^{2)}$ Institute of Space and Astronautical Science, Kanagawa, Japan \\ ${ }^{3)}$ Department of Aeronautics and Astronautics, Tokai University, Kanagawa, Japan \\ ${ }^{4)}$ Department of Physics, Rikkyo University, Tokyo, Japan \\ ${ }^{5)}$ National Institute of Polar Research, Tokyo, Japan \\ ${ }^{6}$ Planetary Plasma and Atmospheric Research Center, Tohoku Universiy, Sendai, Japan
}

(Received April 30th, 2008)

\begin{abstract}
The Upper Atmosphere and Plasma Imager (UPI) was launched in 2007, and went to the moon. From the lunar orbit, two telescopes direct toward the Earth. The moon has no atmosphere, which leads no active emission near the spacecraft, thus we have a high quality image of the near-Earth environment. Moreover the moon orbits the Earth once a month and the Earth is observed from many different directions. This is called a "science from the Moon". The two telescopes are mounted on 2-axis gimbal system, Telescope of Extreme ultraviolet (TEX) and Telescope of Visible light (TVIS). TEX detects the O II $(83.4 \mathrm{~nm})$ and He II $(30.4 \mathrm{~nm})$ emissions scattered by ionized oxygen and helium, respectively. The targets of EUV imaging are the polar ionosphere, the polar wind, and the plasmasphere and the inner magnetosphere. The maximum spatial and time resolutions are $0.09 \mathrm{Re}$ and 1 minute, respectively.
\end{abstract}

Key Words: Plasmasphere, Polar wind, Polar ionosphere, Magnetosphere, EUV imaging

\section{Introduction}

Observations by polar orbiting satellites such as Dynamic Explorer 1 (DE-1) and AKEBONO (EXOS-D) found that the upward flux of $\mathrm{O}^{+}$was comparable to that of $\mathrm{H}^{+}$, especially under an active geomagnetic condition and during a period of a high solar activity ${ }^{1)}{ }^{2)}$. Furthermore, GEOTAIL observed the cold dense $\mathrm{O}^{+}$flow of the ionospheric origin in the distant tail lobe ${ }^{3)}$ ) . The difference between the rate of $\mathrm{O}^{+}$outflow from the polar ionosphere and that of $\mathrm{O}^{+}$escape from the magnetosphere to interplanetary space indicates that there should be unknown transport processes for $\mathrm{O}^{+}$in the magnetosphere 5) The 2-Dimensional O II imagery, which shows us a global $\mathrm{O}^{+}$distribution, is expected to identify the transport routes and mechanisms of the cold $\mathrm{O}^{+}$ions and to reveal a quantitative balance between the supply and loss including thermal plasma.

On the other hand, our knowledge of the Earth's plasmasphere has increased steadily owing to a number of in situ plasma measurements during the past several decades. The plasmasphere is filled with cold ions such as $\mathrm{H}^{+}, \mathrm{He}^{+}$, and a small amount of $\mathrm{O}^{+}$and is filled up to high density (about 100 ions $/ \mathrm{cm}^{3}$ ). The outer boundary, the plasmapause, is interpreted as a separatrix between closed and open convection trajectories ${ }^{6)}$. Under a steady convection electric field condition, the plasmapause is considered to form a "teardrop" shape on the equatorial plane. The traditional models indicate that the plasmapause moves closer to the Earth when the large-scale convection electric field is enhanced. Then plasma which was previously on a closed drift path changes to an open drift path. As a result, the open drift path carries the plasma sunward, creating a plasmaspheric tail.

The remote-sensing methods using the extreme ultraviolet (EUV) emission of $\mathrm{He}^{+}$(He II $30.4 \mathrm{~nm}$ ) and $\mathrm{O}^{+}$ (O II $83.4 \mathrm{~nm}$ ) have been expected to be a powerful tool to provide global perspectives on the escaping processes ${ }^{7)}$ 8) 9) , because conventional in-situ plasma particle measurement methods cannot detect plasma particles far from the satellite or thermal plasmas. The fundamental technology to detect He II emission began with the rocket experiments in the $70 \mathrm{~s}$ and $80 \mathrm{~s}$ 10) 11) 12) 13). These measurements clarified that optical thickness of $\mathrm{He}^{+}$ions is very thin and intensity is very low (10 Rayleigh at most). Also, they clearly showed feasibility to image the plasma distribution around the Earth. In the 90s, technological developments in EUV optics were reported in several articles ${ }^{14)}{ }^{15)}$, and breakthrough in multilayer coating technique was firstly demonstrated by the sounding rocket experiment ${ }^{16}$ ). Later, the 2-D He II imaging of the terrestrial plasmasphere from its outside was done by both the Planet-B (Nozomi) spacecraft ${ }^{17)}{ }^{18)}$ 19) and the Imager for magnetopause-to-Aurora Global Exploration (IMAGE) mission ${ }^{20)}$. Cold $\mathrm{He}^{+}$ions in the near-Earth plasma sheet were also optically observed by Planet-B ${ }^{21)}$. The technological development for detecting 
$30.4 \mathrm{~nm}$ radiation is in progress ${ }^{22)}$. The optical observations of oxygen ions around the Earth have not been yet performed, because of difficulty to reject the bright H Ly- $\alpha$ line from the geocorona. We had developed primitive equipment named the eXtreme UltraViolet (XUV) sensor that has the thick indium film for the band pass filter. It has enough high efficiency ratio of the O II emission to the H Ly- $\alpha$ line ${ }^{23)}$. On December 4, 2000, it flew onboard the sounding rocket SS-520-2 to investigate the mechanism of ion acceleration and/or heating at the cusp/cleft region. The XUV sensor successfully detected the O II emission from the uppermost part of the polar ionosphere. The altitudinal variation from 150 through $1100 \mathrm{~km}$ indicated the existence of $\mathrm{O}^{+}$ions beyond the polar ionosphere and suggested that the $\mathrm{O}^{+}$ions energized in the cusp/cleft region may drift to the uppermost part of the polar ionosphere.

Using an upgrade version of this instrument we planed to obtain the O II images of the polar wind from the lunar orbit with the SELenological and ENgineering Explorer (SELENE). The SELENE (KAGUYA) was launched by the H-IIA rocket in 2007 to be put into the orbit around the moon. In KAGUYA project, we carry out the scientific observations of the moon, at the moon, and from the moon. The Upper atmosphere and Plasma Imager (UPI) on KAGUYA takes 2-D visible and extreme ultraviolet images of atomic and plasma distribution in the upper atmosphere and ionosphere and around the Earth. The component has two telescopes; one is Telescope for VISible light (UPI-TVIS), and the other is Telescope for EXtreme ultraviolet light (UPI-TEX). The UPI-TVIS imager detects the four emission lines (427.8, 557.7, $589.3,630.0 \mathrm{~nm}$ ) to simultaneously take auroral images around both of Earth's polar regions, and the UPI-TEX imager detects the resonance scattering emissions of oxygen ion (O II: $83.4 \mathrm{~nm}$ ) and helium ion (He II: $30.4 \mathrm{~nm}$ ) to take images of near-Earth plasmas ${ }^{24)}$. In this paper we present the design of the UPI-TEX imager and the calibrated performance.

\section{Science Target}

The UPI-TEX instrument provides global images of plasmas in the vicinity of the Earth by detecting He II $(30.4 \mathrm{~nm})$ emission scattered by $\mathrm{He}^{+}$ions and OII $(83.4$ $\mathrm{nm})$ emission by $\mathrm{O}^{+}$ions. The observational targets are the plasmasphere, the polar wind, and the magnetosphere. In the following subsections, we present the scientific motivations and open questions which have not been resolved by past satellite observations.

\subsection{Global Image of the Plasmasphere}

The intensity of He II $(30.4 \mathrm{~nm})$ emission from the main body of the plasmasphere is reported as about $5 \mathrm{R}$ by Nakamura et al. [2000] ${ }^{17)}$. This result is consistent with early measurements of 1-10 $\mathrm{R}$ done by sounding rockets from the inside-out view ${ }^{10)}$ and with simulational EUV images of the plasmasphere ${ }^{25}$. The intensity from the outer boundary of the plasmasphere has not been clarified yet by IMAGE mission, but reported to be in the range of 0.1-5 Rayleigh by the Planet B satellite ${ }^{18)}$. The intensity of 0.1-0.5 $\mathrm{R}$ is considered to be a lower threshold level of the detection to grasp the global shape of the plasmasphere.

\subsection{Plasmasphere Response to the Interplanetary Magnetic Field (IMF)}

Murakami et al. [2007] used the sequential EUV images of the plasmasphere obtained by NASA's IMAGE satellite, and investigated the plasmaspheric response time to the solar wind electric field which was measured by solar monitor (ACE satellite) ${ }^{26)}$. They showed that the plasmapause response to the southward turning of the IMF takes 10-30 minutes, and average 18 minutes. It is consistent with time scale derived from the ionospheric observations on the ground stations 27) 28) 29) 30) 31). From this reason, they concluded that the electric field penetrates from the magnetopause to the inner magnetosphere through the ionosphere. But they also insisted that due to limited EUV data, they found only 16 events, the result should be re-investigated by more completed data set of EUV images. The IMAGE satellite orbits near the Earth. Therefore, it cannot always monitor the whole plasmasphere. There are at least a few hours intervals from image to image. That makes difficult to estimate time-lag between the IMF arrival at the magnetosphere and plasmasphere evolution. TEX observation improves this difficulty, because KAGUYA provides the best platform to command a panoramic view of the whole plasmasphere always. As cited above, the intensity of 0.1-0.5 $\mathrm{R}$ is a lower threshold level to grasp the plasmaspheric response.

\subsection{Net escape rate of Earth's oxygen to space}

The observed polar outflow rate for $\mathrm{O}^{+}$ions corresponds to the loss of about $18 \%$ of the present-day atmospheric oxygen over 3 billion years. However, part of this apparent loss can actually be returned to the atmosphere. Examining loss rates of four already-identified escape routes with high-altitude spacecraft observations, Seki et al. (2002) showed that the total oxygen loss rate inferred from current knowledge is about one order of magnitude smaller than the polar $\mathrm{O}^{+}$ outflow rate ${ }^{32)}$. Then, they suggested that there may be a substantial return flux from the magnetosphere to the low-latitude ionosphere, also implied that it may indicate the existence of unknown loss process for terrestrial oxygen. Otherwise, the net escape loss over 3 billion years may drop to about $2 \%$ of the current atmospheric oxygen content. This issue is very important not only for magnetosphere physics but also for the planetology.

Photometric observation is very useful to resolve this issue, because in-situ measurement is difficult to observe the escape of cold $\mathrm{O}^{+}$ions at energies below $50 \mathrm{eV}$ without spacecraft potential control ${ }^{32)}$.

\subsection{Continuous Leakage of Plasmaspheric Materials}

Recent studies have revealed another feature of the plasmasphere. According to in-situ plasma measurements carried out on multiple geosynchronous satellites, the 
standard teardrop model of the plasmasphere, where the bulge size and location are determined by theconvection electric field strength, is not a completely comprehensive description even under low geomagnetic activity ${ }^{33)}$. Furthermore, Matsui et al. [1999] have reported that GEOTAIL on a higher $\mathrm{L}$ value path $(\mathrm{L} \sim 10)$ often found plasmaspheric materials independent of $\mathrm{Kp}^{34)}$. They also have concluded that cold plasma continuously convected toward the magnetopause. These results force us to verify the classical understanding and morphology on the plasmasphere/plasmapause which were constructed in the 1960s.

According to Matsui's statistical analysis, the structure of cold ions along the GEOTAIL path $(\mathrm{L}>10)$ is quasi-stable with density of $2-10 \mathrm{~cm}^{-3}$. If we assume that $10 \%$ of such a population consists of $\mathrm{He}+$ ions, that they spread along the dusk-to-dawn direction of $10 \mathrm{Re}$, and that the g-factor of He II $(30.4 \mathrm{~nm})$ emission is $2 * 10^{-5}$ (ion $^{-1}$ $\left.\mathrm{s}^{-1}\right)$, then the intensity of He II $(30.4 \mathrm{~nm})$ from this source is estimated at $0.026-0.13 \mathrm{R}$. Thus it is needed to construct optics with a lower threshold level of about 0.02 $\mathrm{R}$ to identify this unique phenomenon.

\subsection{Plasmasphere Refilling}

The refilling of the plasmasphere has brought considerably theoretical interest for several decades (see "Plasmasphere Refilling" special section in Journal of Geophysical Research, volume 97, issue A2, pp. 1047-1179, 1992). There were important studies for the plasmasphere refilling in the 1960s and early 1970s, both observations ${ }^{35)}$ 36) 37) and theory or modeling 38) 39) 40), which addressed various refilling problems. One of the unsolved and highlighted issues is how plasma distribution approaches a diffusive equilibrium state under the refilling, where plasma is supplied from the conjugate ionospheres through field-aligned supersonic flows. Most models dealing with refilling of the plasmasphere rely on initial conditions such as plasma density, flow velocity, and temperature in an empty flux tube. However, there is no theoretical basis to decide on the initial distributions, nor is there firm guidance from the observations. Because of little information, the initial conditions are arbitrarily chosen in the models. The choice is generally only based on the fact that the equatorial plasma density in a depleted flux tube is as low as $1 \mathrm{~cm}^{-3}$. We do not know how this low equatorial density connects with the high ionospheric density.In this regard, systematic observation along a depleted flux tube should reveal the subsequent refilling process. Such observation, however, is impossible to be conducted by using a single satellite, because it is impossible to know latitudinal and longitudinal distributions of plasma simultaneously.

The EUV imaging is a promising method to overcome the difficulty. From the theoretical considerations, time resolution of 30 -minute is necessary to examine the refilling issue. The measured He II $(30.4 \mathrm{~nm})$ intensity of the refilling trough region is $0.02-0.1 \mathrm{R}$ as cited above. TEX should achieve the capability of time and spatial resolutions.

\subsection{Inconsistency of Old and New Topic about the plasmasphere}

The subject for continuous leakage of cold plasma introduced in Section 2.4 may be related to the issue of the plasmasphere refilling. On one hand, in recent studies such as Matsui's investigation, the rate of ion leakage from the plasmasphere was determined provided that the amount of plasma supplied directly from the ionosphere is not dominant. On the other hand, as for the studies of the plasmasphere refilling, it is difficult to determine the evolution of the content in the same flux tubefrom the in situ observation, because a flux tube drifts regardless of a satellite orbital motion. The early measurements of refilling rate of ionospheric plasma might include the contribution of plasma leakage from the inner plasmasphere. As a result, the refilling rate may be overestimated.The EUV observation provides promising clues for the verification of the above two processes, i.e., the plasmasphere refilling and a continuous leakage of plasmaspheric ions.

\subsection{Cold Ions in the Plasma Sheet}

It is well known that the plasma sheet is mainly populated with hot $(\mathrm{keV}) \mathrm{H}+$ and $\mathrm{O}+$ ions and involves a small amount of $\mathrm{He}+$ ions. The polar wind is the most substantial source flux of low-energy ions entering the near-Earth plasma sheet (XGSM>-30 Re). The cold plasma in the polar wind is energized up to several $\mathrm{keV}$ at the entry to the plasma sheet by a number of possible mechanisms ${ }^{41)}$. There is an open question on plasma density which cannot be answered with current data. Chappell et al. [1987] estimated the average He+ density in the plasma sheet on the basis of the outflow flux of $\mathrm{He}+$ ions in the polar region ${ }^{43)}: 0.007 \mathrm{~cm}^{-3}$ at quiet times and $0.035 \mathrm{~cm}^{-3}$ at active times. His numbers exceed a density of $0.005 \mathrm{~cm}^{-3}$ from in situ measurements ${ }^{44)}$. He suggested that the difference is due to the existence of an invisible low-energy plasma $(<10 \mathrm{eV})$ which had never been observed, because spacecraft are typically charged to positive potentials exceeding ion energy ${ }^{43)}$. His estimations correspond to the column density of 1.3 $6.7 \times 10^{8} \mathrm{~cm}^{-2}$ from the dusk-to-dawn view of $30 \mathrm{Re}$ optical length. If a typical g-factor of $2 \times 10^{-5}\left(\mathrm{~s}^{-1}\right.$ ion $\left.^{-1}\right)$ is assumed, the intensities of $\mathrm{He}$ II $(30.4 \mathrm{~nm})$ are calculated as 0.003-0.013 R. Yoshikawa et al. [2000] also reported the signal up to $0.02 \mathrm{R}$ was detected from the outside of the plasmasphere ${ }^{18)}$, but due to a low spatial resolution of the instrument, they could not completely identify the origin. TEX observation on the lunar orbiter surely identifies the origin.

Study of this topic does not need high time-resolution EUV image. The photometric measurement of the plasma sheet with a detection capability of 0.01-0.02 $\mathrm{R}$ with the spatial resolution of 3 Re should bring a definite conclusion on it.

\section{Instrumentation}

Effective imaging of the near-Earth plasma distribution 


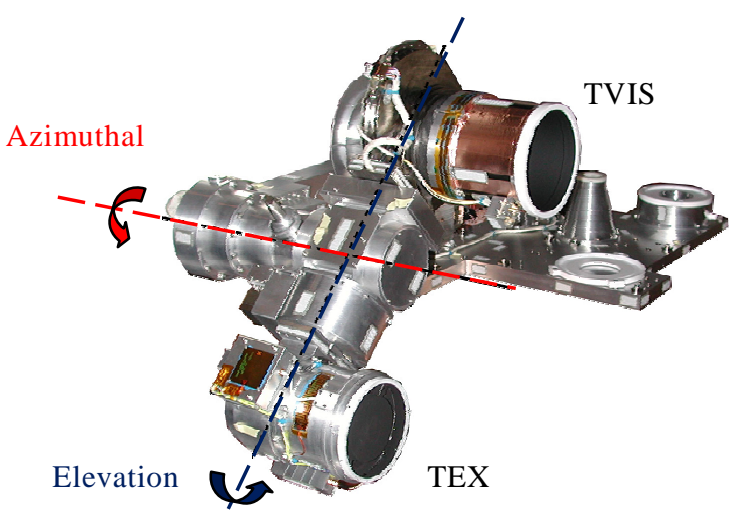

Fig. 1. Upper atmosphere and Plasma Imager (UPI) aboard KAGUYA satellite. Two telescopes are installed on the equatorial mounting (motor-controlled azimuthal and elevation axes) gimbal. After the insertion to the lunar orbit, the system is open (left panels) in order to make the two telescopes ready to point to the Earth. Pointing accuracy of the equatorial mounting is 3.24" around Azimuthal and 2.68" around Elevation axis.

requires global 'snapshots' with wide field-of-view (FOV). KAGUYA provides us an ideal platform that commands a panoramic view of the near-Earth circumstance. Our telescope of extreme ultraviolet is mounted on 2-axis gimbal system together with Telescope of Visible light (TVIS) as shown in Figure 1. Pointing accuracies of the equatorial mounting are 3.24" around Azimuthal and 2.68" around Elevation axes. These correspond to the spatial resolution of $5 \mathrm{~km}$ on the Earth's surface. The UPI-TEX imager is a type of normal-incidnence telescope with a split thin metal filter, which is made of $\mathrm{Al} / \mathrm{C}$ and $\mathrm{In}$, in order to detect the resonance scattering emissions of helium ions (He II : $30.4 \mathrm{~nm}$ ) and oxygen ions (O II : 83.4 $\mathrm{nm})$. The science goals are mainly

1. To understand a global plasma distribution in the inner magnetosphere, and

2. To study outflow mechanisms of oxygen ions from the polar ionosphere.

The cold plasma in the plasmasphere also has active response at the high magnetic activity, contrary to a traditional understanding of the plasmaspheric formation. Recent observations have found that the heavy ions like oxygen ions could also flow out. The remote sensing at $\mathrm{O}$ II by TEX is the first image all over the world and will investigate the nature.

Optics in TEX consists of a multilayer coated mirror to increase the reflectivity at $30.4 \mathrm{~nm}$, a split metallic thin filter, and microchannel plates to pick up photon events (Figure 2). High-voltage power supply (HVPS) is installed at one side as shown in Figure 2, and preamplifier unit is contained along the other side. Survival heaters for the main body of the instrument, the HVPS and the preamplifier (not shown in Figure2) are installed. The key points for the O II $(83.4 \mathrm{~nm})$ and $\mathrm{He}$ II $(30.4 \mathrm{~nm})$ imagings are (1) to eliminate the contamination from $\mathrm{H} \mathrm{I}$ (Ly- $\alpha$, which is emitted from the geocorona to have the intensity of $10 \mathrm{kR}$ at maximum ${ }^{45)}$ and (2) to enhance the detection efficiency at $30.4 \mathrm{~nm}$.

\subsection{Total sensitivity}

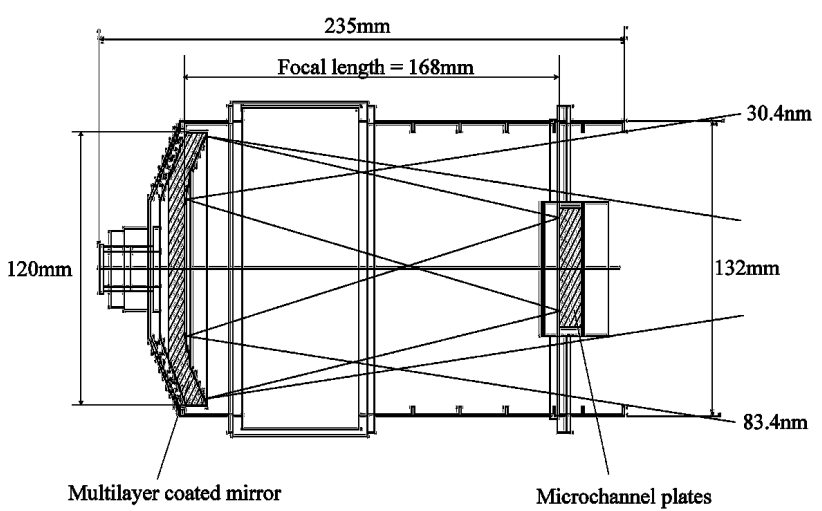

Fig. 2. Configuration of Telescope of Extreme ultraviolet (TEX) boaeded on the KAGUYA satellite. Main optical components are a multilayer coated mirror, a split metal thin filter, microchannel plates.

The TEX has a full circular field-of-view (FOV) of 10 degrees, and the $128 \times 128$ bins corresponding to the spatial resolution of $0.09 \mathrm{Re}$ on the Earth surface from the lunar orbit. Half of FOV (128x64 bins) is used for O II $(83.4 \mathrm{~nm})$ detection, the other is for He II $(30.4 \mathrm{~nm})$. The signal count rate $\mathrm{N}$ [cps] of the emission is represented by the following equations,

$$
\mathrm{N}=10^{6} / 4 \pi \cdot \mathrm{I} \cdot \mathrm{S} \cdot \Delta \cdot \mathrm{T}_{\text {Filter }} \cdot \mathrm{R}_{\text {mirror }} \cdot \mathrm{E}_{\mathrm{MCP}} \text { (1) }
$$

Where $\mathrm{I}$ is the intensity of the emission [Rayleigh], $\mathrm{S}$ is an entrance aperture $\left[\mathrm{cm}^{2}\right], \Delta$ is the sold angle of identical FOV, $\mathrm{T}_{\text {Filter }}$ is transmittance, $\mathrm{R}_{\text {mirror }}$ is a mirror's reflectivity, and $\mathrm{E}_{\mathrm{MCP}}$ is an quantum efficiency of MCP. The telescope has the total efficiency of $0.014 \mathrm{cps} / \mathrm{R}$ for the He II $(30.4 \mathrm{~nm})$ bin and $0.0036 \mathrm{cps} / \mathrm{R}$ for O II $(83.4$ $\mathrm{nm})$ bin.

In the following, we estimate Signal-to-Noise Ratio (SNR) during observation. The detector behaves as an ideal photon counter so that signal corresponds to the number of photon events collected during an exposure period $\left(\mathrm{t}_{\mathrm{exp}}\right)$ and noise is the square root of signal.

Instrumental background (noise count from MCPs in the detector unit) is a primary noise source. The MCPs manufactured by Hamamatsu Photonics Co. had the noise count by $10.4 \mathrm{cps} / \mathrm{cm}^{2}$ in our previous planetary mission, although the noise count in the laboratory was below $1 \mathrm{cps} / \mathrm{cm}^{2}{ }^{18)}{ }^{19)}$. This is due to cosmic ray and/or high energy particle bombardments in the magnetosphere. For lunar environment, we assume the latter component is negligible but as the worst case analysis, we assume $10.4 \mathrm{cps} / \mathrm{cm}^{2}(0.0065 \mathrm{cps} / \mathrm{bin})$ as dark count in lunar orbiter.

Second noise source is a contamination from $\mathrm{He} \mathrm{I}$ $(58.4 \mathrm{~nm})$ and Ly- $\alpha$. emissions. As stated above, Ly- $\alpha$ is sufficiently reduced by the metallic filter on both sides. The intensity of Ly- $\alpha$ is insensitive to our estimation of SNR. In the following discussion, we assumed and fixedthe Ly- $\alpha$. intensity at $5 \mathrm{kR}$. The other possible 
contamination is He I $(58.4 \mathrm{~nm})$ emission. This is
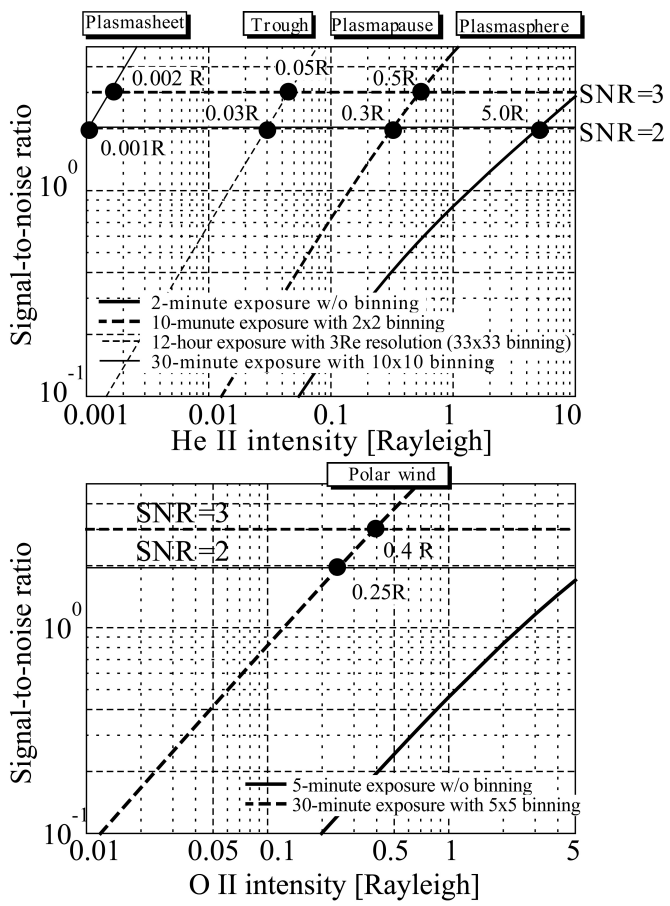

Fig. 3. (Upper panel) Expected Signal-to-Noise Ratios for He II (30.4nm) observation. The SNR is insensitive to ionospheric contamination at $121.6 \mathrm{~nm}$. (Lower panel) Expected SNR for O II $(83.4 \mathrm{~nm})$ observation. The observation is free of ionospheric He I and Ly-alpha contaminations in the range of $10-500 \mathrm{R}$ for $\mathrm{He} \mathrm{I}$ $(58.4 \mathrm{~nm})$ and $1 \mathrm{k}-30 \mathrm{kR}$ for Ly-alpha.

fairly-well reduced by the filter, but potentially contaminates our observation. We assume the geocoronal $\mathrm{He}$ I $(58.4 \mathrm{~nm})$ intensity to be $500 \mathrm{R}$ at the most ${ }^{8)}$ and interstellar He I $(58.4 \mathrm{~nm})$ to be $10 \mathrm{R}^{23)}$.

During the measurement, a detector pixel sees the EUV signal $\left(N_{\text {Signal }}\right)$, measured in cps/bin and the background ( $N_{\text {Background: }}$ instrumental background plus contaminations from the other EUV emissions), measured in the same units. And the number of signal counts is the total observed counts minus the background

$$
\begin{aligned}
\mathrm{N}_{\text {Total }} & =\mathrm{N}_{\text {Signal }}+\mathrm{N}_{\text {Background }} \\
\mathrm{N}_{\text {Signal }} & =\mathrm{N}_{\text {Total }}-\mathrm{N}_{\text {Background }} \\
\sigma_{\text {Signal }} & =\sqrt{\sigma_{\text {Total }}^{2}+\sigma_{\text {Background }}^{2}} \\
& \approx \sqrt{\sigma_{\text {Signal }}^{2}+2 \cdot \sigma_{\text {Background }}^{2}} \\
& \approx \sqrt{\mathrm{N}_{\text {Signal }}+2 \cdot \mathrm{N}_{\text {Background }}} \\
\mathrm{SNR} & =\frac{\mathrm{N}_{\text {Signal }}}{\sigma_{\text {Signal }}}=\frac{\mathrm{N}_{\text {Signal }}}{\sqrt{\mathrm{N}_{\text {Signal }}+2 \cdot \mathrm{N}_{\text {Background }}}}
\end{aligned}
$$

Figure 3 shows SNRs based on the above assumptions. Expected intensities discussed in Section-2 are also indicated. Here we set "SNR=2 or 3" as a norm. For He II $(30.4 \mathrm{~nm})$ observation, the observation mode (2-minute exposure and $0.09 \mathrm{Re}$ resolution) can identify the main body of the plasmasphere with a high reliability $(\mathrm{SNR}=3)$. Also, identifications of plasmapause and refilling region in the trough discussed in Section-2 are feasible with a fairly good SNR. Imaging of the Plasmasheet is the most challenging target, but we will be able to achieve the science goal against the low sky background of He I (10R).

Imaging polar wind by $\mathrm{O}$ II $(83.4 \mathrm{~nm})$ is also challenging target, but the 30-minute exposure with 0.5 $\mathrm{Re}$ resolution makes visible the polar wind with $\mathrm{SNR}=2$.

\section{Summary}

We can image near-Earth cold plasmas at O II (83.4nm) and He II $(30.4 \mathrm{~nm})$ emissions by UPI-TEX instrument aboard KAGUYA satellite. The UPI-TEX instrument has enough performance to detect the oxygen ion outflow, the transport route from the polar ionosphere into the magnetosphere, and the plasmasphere. The 2-Dimensional (2-D) O II imagery identifies the transport routes and mechanisms of the cold $\mathrm{O}^{+}$ions and to reveal a quantitative balance between the supply and loss including thermal plasma. On the other hand, the detection of He II $(30.4 \mathrm{~nm})$ by the TEX instrument is devoted to the new challenge of imaging of magnetosphere (plasmasheet) as well as conventional plasmasphere physics.

\section{Acknowledgements}

Authors thank to all the members of KAGUYA project team for their effort to lead the successful mission.

\section{References}

1) Chandler, M. O., J. H. Waite Jr., and T. E. Moore: Observations of polar ion outflows, J. Geophys. Res., 96 (1998), pp.1421-1428.

2) Abe, T., B. A. Whalen, A. W. Yau, R. E. Horita, S. Watanabe, and E. Sagawa: EXOS D (Akebono) suprathermal mass spectrometer observations of the polar wind, J. Geophys. Res., 98 (1993), pp.191-.203

3) Seki, K., M. Hirahara, T. Terasawa, I. Shinohara, T. Mukai, Y. Saito, S. Machida, and T. Yamamoto: Coexistence of Earth-origin $\mathrm{O}+$ and solar wind-origin $\mathrm{H}+/ \mathrm{He}++$ in the distant magnetotail, Geophys. Res. Lett., 23 (1996), pp.985-988.

4) Seki, K., M. Hirahara, T. Terasawa, T. Mukai, and S. Kokubun: Properties of $\mathrm{He}+$ beams observed by Geotail in the lobe/mantle regions: Comparison with $\mathrm{O}+$ beams, J. Geophys. Res., 104 (1999), pp.6973-6986.

5) Seki, K., R. C. Elphic, M. Hirahara, T. Terasawa, and T. Mukai: On atmospheric loss of oxygen ions from earth through magnetospheric processes, Science, 291 (2001), pp.1939-1941.

6) Nishida, A.: Formation of plasmapause, or magnetospheric plasma knee, by the combined action of magnetospheric convection and plasma escape from the tail, J. Geophys. Res., 71 (1966), pp.5669.

7) Chiu, Y. T., R. M. Robinson, G. R. Swenson, S. Chakrabarti, and D. S. Evans: Imaging the outflow of ionospheric ions into the magnetosphere, Nature, 322 (1986), pp.441-444.

8) Meier, R. R.: Ultraviolet spectroscopy and remote sensing of the upper atmosphere, Space Sci. Rev., 58 (1991), pp.1-185.

9) Williams, D. J., E. C. Roelof, and D. G. Mitchell: Global magnetospheric imaging, Rev. Geophys., 30 (1992), pp.183-208.

10) Ogawa, T., and T. Thomatsu: Sounding rocket observation of helium 304 and 584-A glow, J. Geophys. Res., 76 (1971), 
pp.6136.

11) Meier, R. R., and C. S. Weller: EUV resonance radiation from helium atoms and ions in the geocorona, J. Geophys. Res., 77 (1972), pp.1190-1204.

12) Paresce, F., C. S. Bowyer, and S. Kumar: On the distribution of $\mathrm{He}+$ in the plasmasphere from observations of resonantly scattered He II 304-A radiation, J. Geophys. Res., 79 (1974), pp.174-178.

13) Chakrabarti, S., F. Paresce, C.S. Bowyer, Y. T. Chiu, and A. Aikin: Plasmaspheric helium ion distribution from satellite observations of He II 304A, Geophys. Res. Lett., 9 (1982), pp.151-154.

14) Cotton, D. M., R. Conant, and S. Chakrabarti: Wide-angle geocoronal telescope: a He-II 304-A plasmaspheric imager, Optical Engineering, 32 (1993), pp.3170-3173.

15) Chakrabarti, S.: Magnetospheric Imagery and Atmospheric Remote Sensing, Optical Engineering, 32 (1993), pp.3007-3008.

16) Yoshikawa, I., M. Nakamura, M. Hirahara, Y. Takizawa, K. Yamashita. H. Kunieda, T. Yamazaki, K. Misaki, and A Yamaguchi: Observation of $\mathrm{He}$ II emission from the plasmasphere by a newly developed EUV telescope on board sounding rocket S-520-19, J. Geophys. Res., 109 (1997), pp.19897-19902.

17) Nakamura, M., I. Yoshikawa, A. Yamazaki, K. Shiomi, Y. Takizawa, M. Hirahara, K. Yamashita, Y. Saito, and W. Miyake: Terrestrial plasmaspheric imaging by an extreme ultraviolet scanner on Planet-B, Geophys. Res. Lett., 27 (2000), pp.141.

18) Yoshikawa, I., A. Yamazaki, K. Shiomi, K. Yamashita, Y. Takizawa, and M. Nakamura: Evolution of the outer plasmasphere during low geomagnetic activity observed by the EUV scanner onboard Planet-B, J. Geophys. Res., 105 (2000), pp.27777-27790

19) Yoshikawa, I., A. Yamazaki, K. Shiomi, M. Nakamura, K Yamashita, Y. Saito, M. Hirahara, Y. Takizawa, W. Miyake, and S. Matsuura: Development of a compact EUV photometer for imaging the planetary magnetosphere, J. Geophys. Res., 106 (2001), pp.26057-26074

20) Burch, J. L, S. B. Mende, D. G. Mitchell, T. E. Moore, C. J. Pollock, B. W. Reinisch, B. R. Sandel, S. A. Fuselier, D. L. Gallagher, J. L. Green, J. D .Perez, and P. H. Reiff: Views of earth's magnetosphere with the IMAGE satellite, Science, 291 (2001), pp.619-624.

21) Murakami, G., K. Yoshioka, and I. Yoshikawa: Development of $\mathrm{Mg} / \mathrm{SiC}$ multilayer mirrors, Proceeding of SPIE, $\mathbf{6 3 1 7}$ (2006), pp.631714-1.

22) Yoshikawa, I., A. Yamazaki, K. Shiomi, K. Yamashita, Y. Takizawa, and M. Nakamura, Photometric measurement of cold helium ions in the magnetotail by an EUV scanner onboard Planet-B: Evidence of the existence of cold plasmas in the near-Earth plasma sheet, Geophys. Res. Lett., 27 (2000), pp.3567-3570.

23) Yamazaki, A., S. Tashiro, Y. Nakasaka, I. Yoshikawa, W. Miyake, and M. Nakamura, Sounding-rocket observation of O II 83.4-nm emission over the polar ionosphere, Geophys. Res. Lett., 29 (2002), pp.1-1.

24) Yoshikawa, I., A. Yamazaki, G. Murakami, K. Yoshioka, S. Kameda, F. Ezawa, T. Toyota, W. Miyake, M. Taguchi, M. Kikuchi, and M. Nakamura: Telescope of extreme ultraviolet (TEX) onboard SELENE:science from the Moon, Earth Planets Space, 60 (2008), pp.407-416.

25) Roelof, E. C., B. H. Mauk, Barry, and R. R. Meier: Instrument requirements for imaging the magnetosphere in extreme ultraviolet and energetic neutral atoms derived from computer-simulated images, Proc. SPIE, 1744 (1992), pp.19-30.

26) Murakami, G., M. Hirai, and I. Yoshikawa: The plasmapause response to the southward turning of the IMF derived from sequential EUV images, J. Geophys. Res., 112 (2007), A06217,
doi:10.1029/2006JA012174.

27) Ridley, A. J., G. Lu, C. R. Clauer, and V. O. Papitashvili: A statistical study of the ionospheric convection response to changing interplanetary magnetic field conditions using the assimilative mapping of ionospheric electrodynamics technique, J. Geophys. Res., 103 (1998), pp.4023-4040.

28) Ruohoniemi, J. M., and R. A. Greenwald: The response of high-latitude convection to a sudden southward IMF turning, Geophys. Res. Lett., 25 (1998), pp.2913-2916.

29) Lu, G., T. E. Holzer, D. Lummerzheim, J. M. Ruohoniemi, P. Stauning, O. Troshichev, P. T. Newell, M. Brittnacher, and G. Parks: Ionospheric response to the inter-planetary magnetic field southward turning: Fast onset and slow reconfiguration, J. Geophys. Res., 107 (2002), pp.SIA2-1.

30) Kikuchi, T., H. Luhr, T. Kitamura, O. Saka, and K. Schlegel: Direct penetation of the polar electric field to the equator during a DP2 event as detected by the auroral and equatorial magnetometer chains and the EISCAT radar, $J$. Geophys. Res., 101 (1996), pp.17161-17174.

31) Hashimoto, K. K., T. Kikuchi, and Y. Ebihara: Response of the magnetospheric convection to sudden interplanetary magnetic field changes as deduced from the evolution of partial ring currents, J. Geophys. Res., 107 (2002), pp.SMP1-1.

32) Seki, K., M. Hirahara, T. Terasawa, T. Mukai, and R. Elphic: Dynamics of oxygen ions in the Earth s magnetotail: Geotail and FAST observations, 34th COSPAR Scientific Assembly, 2002, pp.10-19.

33) Moldwin, M. B., M. F. Thomsen, S. J. Bame, D. J. McComas, and K. R. Moore: An examination of the structure and dynamics of the outer plasmasphere using multiple geosynchronous satellites, J. Geophys. Res., 99 (1994), pp.11475-11482.

34) Matsui, H., T. Mukai, S. Ohtani, K. Hayashi, R. C. Elphic, M. F. Thomsen, and H. Matsumoto: Cold dense plasma in the outer magnetosphere, J. Geophys. Res., 104 (1999), pp.25077-25096.

35) Park, C. G.: Whistler observations of the interchange of ionization between the ionosphere and the protonosphere, $J$. Geophys. Res., 75 (1970), pp.4249-4260.

36) Park, C. G., and P. M. Banks: Influence of thermal plasma flow on the mid-latitude nighttime F2 layer - Effects of electric fields and neutral winds inside the plasmasphere, J. Geophys. Res., 79 (1974), pp.4661-4668.

37) Chappell, C. R., K. K. Harris, and G. W. Sharp: The relationship of the plasmasphere and the stable auroral red arcs in the magnetic storm of october 29 to november 7, Astrophys. and Space Sci. Lib., 24 (1971), pp.73.

38) Banks, P. M., A. F. Nagy, and W. I. Axford: Dynamical behavior of thermal protons in the mid-latitude ionosphere and magnetosphere, Planet. and Space Sci., 19 (1971), pp.1053.

39) Schulz, M., and H. C. Koons: Thermalization of colliding ion streams beyond the plasmapause, J. Geophys. Res., 77 (1972), pp.248-254.

40) Grebowsky, J. M.: Time Dependent plasmapause motion, J. Geophys. Res, 75 (1971), pp.6193-6197.

41) Lyons, L. R., and T. W. Speiser: Evidence for current sheet acceleration in the geomagnetic tail, J. Geophys. Res., 87 (1982), pp.2276-2286.

42) Cowley, S. W. H.: Plasma populations in a simple open model magnetosphere, Space Sci. Rev., 26 (1980), pp.217-275.

43) Chappell, C. R., J. H. Waite Jr., and T. E. Moore: The ionosphere as a fully adequate source of plasma for the Earth's magnetosphere, J. Geophys. Res., 92 (1987), pp.5896-5910.

44) Lennartsson, W., and E. G. Shelley: Survey of 0.1- to 16-keV/e plasma sheet ion composition, J. Geophys. Res., 91 (1986), pp.3061-3076.

45) Rairden, R. L., L. A. Frank, and J. D. Craven: Geocoronal imaging with Dynamics Explorer, J. Geophys. Res., 91 (1986), pp.13613-13630. 